\title{
Bilateral Basal Ganglia Calcification: Fahr's Disease
}

Hsein Wei Ooi ${ }^{1}$, Chaozer Er $^{2}$, Ikram Hussain ${ }^{2}$, Navin Kuthiah ${ }^{3}$, Veeraraghavan Meyyur Aravamudan ${ }^{2}$

1. Miscellaneous, Ministry of Health Holdings, Singapore, SGP 2. Internal Medicine, Woodlands Health Campus, Singapore, SGP 3. General Medicine, Woodlands Health Campus, Singapore, SGP

Corresponding author: Hsein Wei Ooi, hseinwei.ooi@mohh.com.sg

\begin{abstract}
Fahr's disease/syndrome is a condition defined as bilateral striato-pallido-dentate calcinosis, a neurodegenerative disease with radiological findings of symmetrical and bilateral idiopathic calcifications of the cerebellum, periventricular white matter, and basal ganglia. Clinical correlation with radiological and a calcium metabolism panel is crucial in differentiating between Fahr's disease and Fahr's syndrome. We describe a case that presented with the clinical feature of a cerebrovascular accident and had an incidental radiological finding of Fahr syndrome. The clinical features, laboratory investigations, and clinical management of Fahr's disease/syndrome will be discussed in detail in the article.
\end{abstract}

Categories: Internal Medicine, Neurology, Radiology

Keywords: fahr syndrome, fahr disease

\section{Introduction}

Fahr's disease was described by Karl Theodor Fahr in 1930 as a rare familial (autosomal dominant) disorder that presented with idiopathic basal ganglia calcification, as seen in the neuroimaging study [1]. This condition is presented clinically with a broad range of neuropsychiatric symptoms and extrapyramidal disorders. A post-mortem examination revealed non-atherosclerotic vascular disease in the centrum semiovale and striatum [2-3]. Herein, we present the case of a male patient who presented with symptoms suggestive of a cerebrovascular accident and had computed tomography (CT) findings which were suggestive of Fahr's syndrome. The lab investigations also showed hypocalcaemia which was also a sign of Fahr's syndrome. This article will emphasize the radiological features, clinical features, diagnostic criteria, and management of Fahr's syndrome/Fahr's disease.

Received 04/01/2019

Review began 05/11/2019 Review ended 05/25/2019 Published 06/01/2019

\section{() Copyright 2019}

Ooi et al. This is an open access article distributed under the terms of the Creative Commons Attribution License CC-BY 3.0., which permits unrestricted use, distribution, and reproduction in any medium, provided the original author and source are credited.

\section{Case Presentation}

The patient was a 77-year-old Chinese male who presented with the acute onset of symptomatic nonvertiginous giddiness (vomiting), nocturnal right wrist numbness, chronic progressive visual blurring, and left-sided hearing loss. However, there was no associated weakness or numbness of the extremities. The patient had a history of hypertension and hyperlipidaemia and had not been taking his antihypertensive agent, statins, or aspirin.

On physical examination, the patient was afebrile, hypertensive with a blood pressure reading of 191/90, a pulse rate of 82 beats per minute, and oxygen saturation of $100 \%$ on room air. No focal motor or sensory deficits were detected at the time of presentation. There were no demonstrable cerebellar signs. Results from the fundoscopic examination were unremarkable. No goitre was palpated. The cardiac and lung examination results were unremarkable.

Laboratory investigations revealed a hypocalcaemia level of $2.12 \mathrm{mmol} / \mathrm{L}$ (normal: 2.25 - $2.5 \mathrm{mmol} / \mathrm{L}$ ) and serum phosphate level of $0.98 \mathrm{mmol} / \mathrm{L}$ (normal: $0.8-1.4 \mathrm{mmol} / \mathrm{L}$ ), although a serum parathyroid level was not evaluated. The renal panel showed acute renal impairment with a serum creatine level of $105 \mathrm{umol} / \mathrm{L}$ (normal: 80 - $95 \mathrm{umol} / \mathrm{L}$ ). The serum electrolytes levels were normal with a sodium of $141 \mathrm{umol} / \mathrm{L}$ (normal: $135-145 \mathrm{umol} / \mathrm{L})$ and potassium of $3.9 \mathrm{umol} / \mathrm{l}(3.5-4.5 \mathrm{umol} / \mathrm{L})$. There was an incidental note of vitamin D insufficiency of $29.5 \mathrm{ng} / \mathrm{mL}$ (normal: 40 - $59 \mathrm{ng} / \mathrm{mL}$ ), subclinical hypothyroidism (free thyroxine (FT4) of 13.1 (7 - $15 \mathrm{mg} / \mathrm{L})$ ), and a thyroid-stimulating hormone (TSH) level of 5.88 (normal: $0.4-4.5 \mathrm{U} / \mathrm{mL}$ ). The electrocardiogram (ECG) showed sinus rhythm and a normal QTc of $453 \mathrm{~ms}$ (normal: 451 - $470 \mathrm{~ms}$ ). A lowdensity lipoprotein (LDL) of $5.06 \mathrm{umol} / \mathrm{L}$ (normal: < $3.4 \mathrm{umol} / \mathrm{L}$ ), high-density lipoprotein (HDL) of 1.03 umol/L (normal: 1 - $1.5 \mathrm{umol} / \mathrm{L}$ ), and triglyceride level of $1.83 \mathrm{umol} / \mathrm{L}$ (normal: $<2.3 \mathrm{umol} / \mathrm{L}$ ) were noted in the screening lipid panel.

CT imaging of the brain demonstrated confluent and asymmetrical calcification of the lentiform nuclei, thalami, corona radiata, and dentate nuclei (Figure 1). There was no evidence of acute intracranial haemorrhage or established territorial infarction. The patient's symptoms resolved after an intramuscular administration of stemetil in the emergency department. Antihypertensive and statins were 


\section{Cureus}

reinstituted in view of the clinical presentation of hypertension urgency, as well as hyperlipidaemia. The patient's acute renal impairment resolved after intravenous and oral rehydration in the general ward.

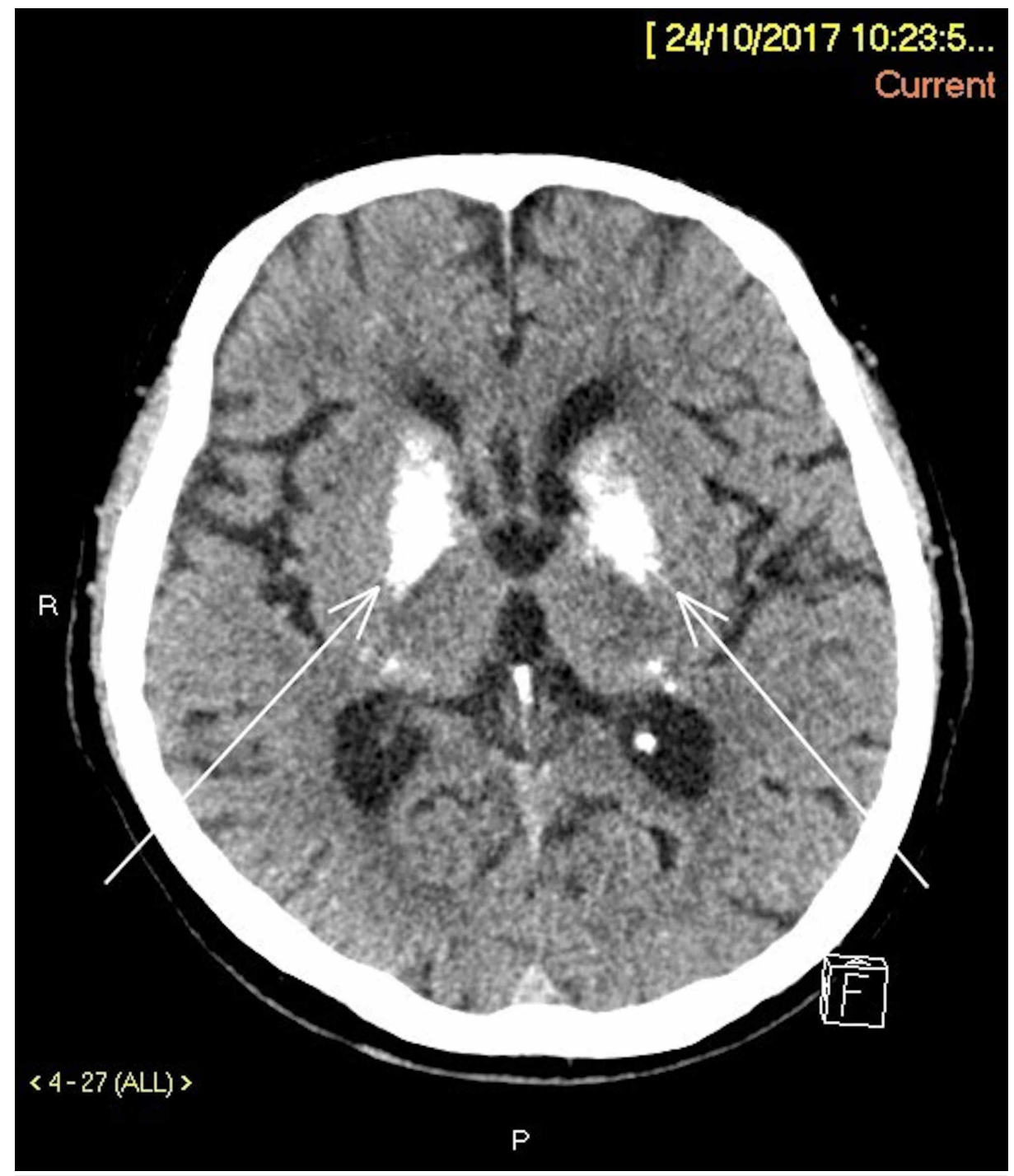

FIGURE 1: Axial Section of the Brain Shows Symmetrical Calcifications in the Corona Radiata (arrows).

Neurology was consulted in view of the radiological findings demonstrated in the CT scan of the brain. The impression of the neurologist was possible Fahr syndrome which could still be incidental and the current clinical presentation could be due to accelerated hypertension. After optimal blood pressure control, he had a complete recovery and was discharged with advice on stroke prevention and blood pressure control.

\section{Discussion}

Although both Fahr's syndrome and Fahr's disease resemble each other in terms of clinical signs and symptoms (e.g., neurological and psychiatric manifestations), there is still a clear distinction regarding the aetiology, location of calcifications, and treatment.

Table 1 is adapted from the diagnostic checklist by Perugula and Lippman to demonstrate the distinctions between these conditions [4]. 


\section{Cureus}

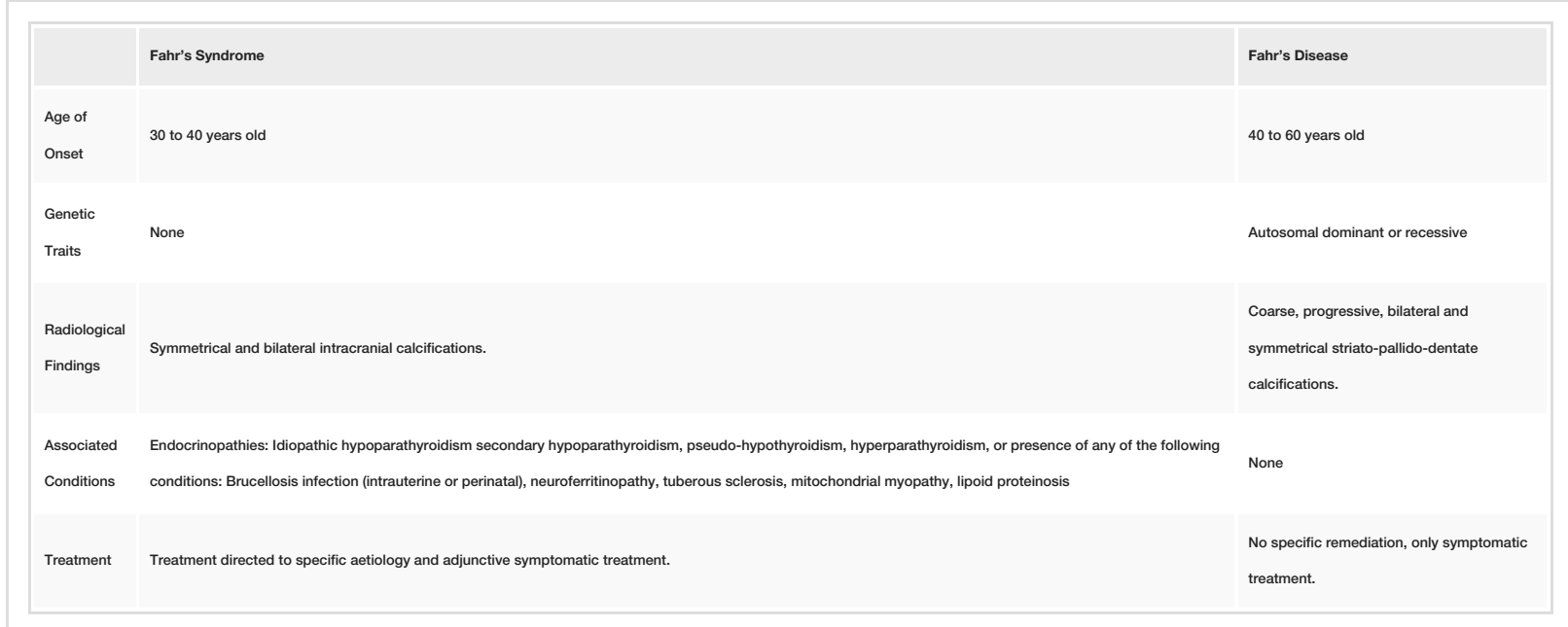

\section{TABLE 1: Diagnostic Features for Fahr's Disease and Fahr's Syndrome}

Table adapted from the diagnostic checklist by Perugula and Lippman [4]

\section{Prevalence}

The exact prevalence of Fahr's syndrome is uncertain; however, intracranial calcifications suggestive of Fahr's syndrome are detected incidentally in approximately $0.3 \%$ to $1.2 \%$ of CT imaging of the brain [2].

\section{Clinical features}

Clinical features of both Fahr's disease and Fahr's syndrome are as listed in Table 2 below [5].

\begin{tabular}{|l|l|}
\hline Neurological & Psychiatric \\
\hline Seizure & Cognitive impairment (dementia/delirium/confusion) \\
\hline Movement disorder & Psychotic symptoms (hallucination/delusion) \\
Pyramidal signs/parkinsonism & Catatonia \\
Gait disorder & Irritability/aggression \\
Sensory changes & Personality disorder/personality change \\
Cerebellar abnormalities (vertigo) & Mood disorder \\
& Anxiety/obsessive behaviour \\
\hline
\end{tabular}

TABLE 2: Clinical Features of Fahr's Disease and Fahr's Syndrome

Pistacchi et al. [5]

\section{Complications}

Other complications or clinical presentations include stroke, orthostatic hypotension, and syncope.

\section{Diagnostic criteria}

Diagnostic criteria for Fahr's syndrome/disease are listed in Table 3 below [6-10]. 


\section{Cureus}

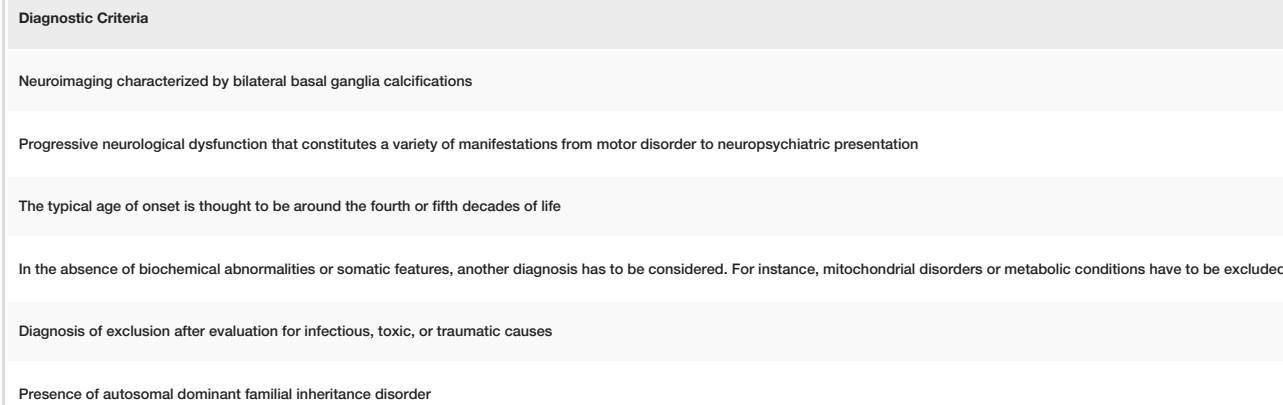

TABLE 3: Diagnostic Criteria of Fahr's Syndrome and Fahr's Disease

Jaworski et al., Saleem et al., Pourshahid et al., Moskowitz et al., Manyam BV [6-10]

\section{Biochemical and haematological investigations}

Baseline biochemical investigations are indicated to rule out other possible diagnoses (Table 4) [7-8].

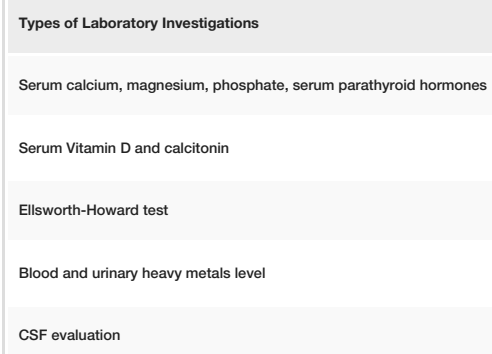

\section{TABLE 4: Laboratory Investigations in Diagnosing Fahr's Disease}

Saleem et al. [7]

CSF: cerebrospinal fluid

\section{Genetic testing}

Molecular genetic testing is indicated if there is a strong family history of autosomal dominant inheritance. SLC20A2 sequencing is the first test to be performed. If no identifiable mutation or deletion of SLC20A2, one must consider PDGFRB sequence analysis [7].

\section{Type of genetic abnormalities}

The exact aetiology of Fahr's syndrome is still unclear. Genetic alteration at chromosome 14 has been suggested as a cause of this condition [3]. It is thought to be autosomal dominant in transmission. The $14 \mathrm{q}$ chromosome is most commonly affected in Fahr's syndrome [11-14].

\section{Radiological findings}

Radiological findings are usually detected incidentally in CT imaging for both Fahr's disease and Fahr's syndrome. These are the most important features as indicated in the diagnostic criteria. Bilateral calcifications of the basal ganglia, gangliocapsular region, and dentate nuclei are the classical radiological findings. Pathologically, calcifications occur in the vascular walls and in the perivascular spaces of arterioles, capillaries, and veins [7]. Laser spectroscopy demonstrated the presence of mucopolysaccharides and other minerals (zinc, phosphorus, chlorine, iron, aluminum, magnesium, and potassium). An MRI study has no significant role in imaging for these conditions. In the interest of MR imaging, the basal ganglia calcifications exhibit a low T2 signal and low to high T1 signal [15].

\section{Management and treatment}


Treatment for Fahr's syndrome is tailored to the underlying associated conditions. Symptomatic treatment is most helpful. Symptomatic treatment can be pharmacological in nature. Table 5 below summarizes the drugs commonly used [16-18].

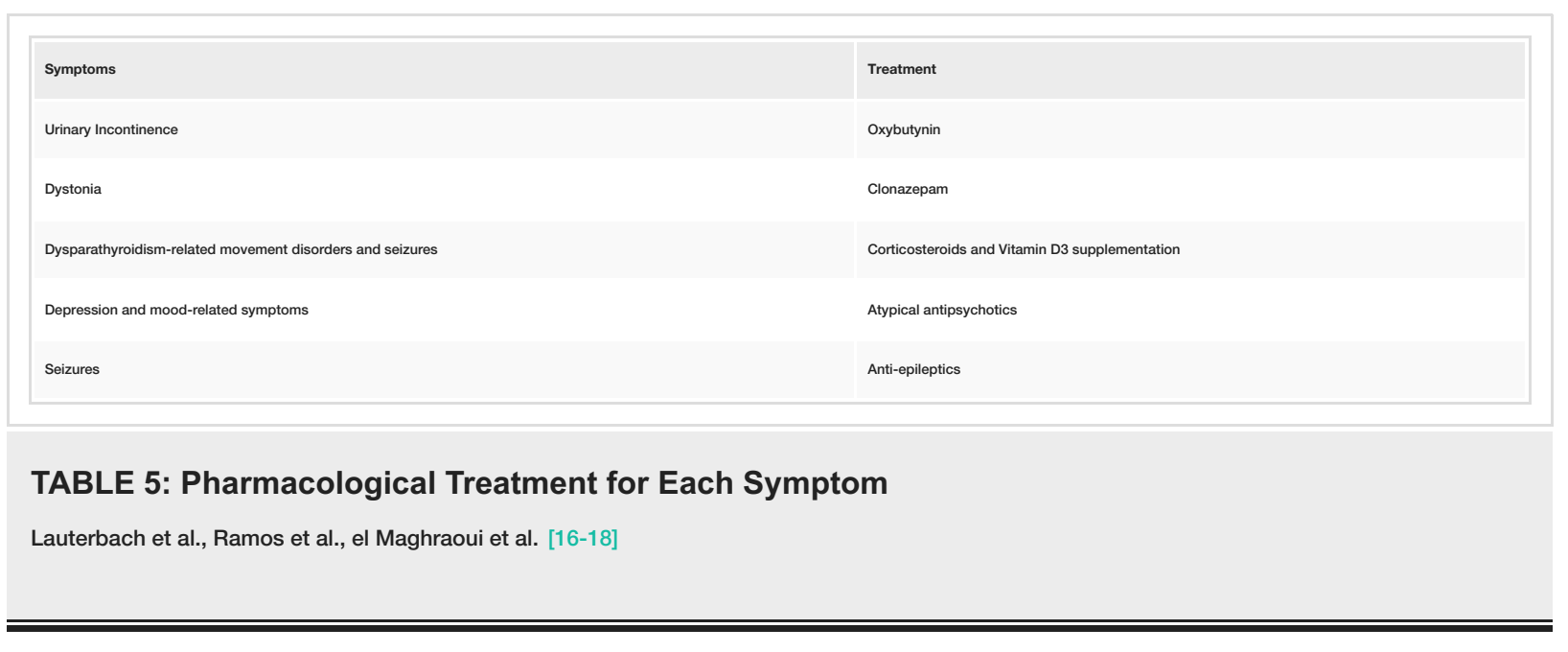

This case was slightly different from the published cases as the clinical presentation was non-specific, but the CT scan findings were suggestive of Fahr syndrome.

\section{Conclusions}

Fahr's disease and Fahr's syndrome have a widespread clinical presentation with radiological findings of bilateral symmetrical basal ganglia and dentate nuclei calcifications. Therefore, it's essentially a diagnosis of exclusion after ruling out metabolic disorders. Treatment is tailored to symptom control for Fahr's disease and correction of underlying metabolic abnormalities.

\section{Additional Information \\ Disclosures}

Human subjects: Consent was obtained by all participants in this study. Conflicts of interest: In compliance with the ICMJE uniform disclosure form, all authors declare the following: Payment/services info: All authors have declared that no financial support was received from any organization for the submitted work. Financial relationships: All authors have declared that they have no financial relationships at present or within the previous three years with any organizations that might have an interest in the submitted work. Other relationships: All authors have declared that there are no other relationships or activities that could appear to have influenced the submitted work.

\section{Acknowledgements}

I will like to acknowledge Dr. Chi Long Ho, Sengkang General Hospital (Singapore), Consultant Radiologist, for sharing other CT scans with features suggestive of Fahr's syndrome/disease.

\section{References}

1. Fahr T: Idiopathische Verkalkung der Hirngefässe (Article in German) . Zentralbl Allg Pathol Pathol Anat. 1930, 50:129-33.

2. Fénelon G, Gray F, Paillard F, Thibierge M, Mahieux F, Guillani A: A prospective study of patients with CT detected pallidal calcifications. J Neurol Neurosurg Psychiatry. 1993, 56:622-25. 10.1136/jnnp.56.6.622

3. Brodaty H, Mitchell P, Luscombe G, Kwok JJ, Badenhop RF, McKenzie R, Schofield PR: Familial idiopathic basal ganglia calcification (Fahr's disease) without neurological, cognitive and psychiatric symptoms is not linked to the IBGC1 locus on chromosome14q. Hum Genet. 2002, 110:8-14. 10.1007/s00439-001-0650-X

4. Perugula ML, Lippmann S: Fahr's disease or Fahr's syndrome?. Innov Clin Neurosci. 2016, 13:45-46.

5. Pistacchi M, Gioulis M, Sanson F, Marsala SM: Fahr's syndrome and clinical correlation: a case series and literature review. Folia Neuropathol. 2016, 54:282-94. 10.5114/fn.2016.62538

6. Jaworski K, Styczyńska M, Mandecka M, Walecki J, Kosior DA: Fahr syndrome: an important piece of a puzzle in the differential diagnosis of many diseases. Pol J Radiol. 2017, 82:490-93. 10.12659/PJR.902024

7. Saleem S, Aslam HM, Anwar M, Anwar S, Saleem M, Saleem A, Rehmani MA: Fahr's syndrome: literature review of current evidence. Orphanet J Rare Dis. 2013, 8:156. 10.1186/1750-1172-8-156

8. Pourshahid S, Salloum MN, Elfishawi M, Barakat M, Basith M: Fahr's disease: a differential to be considered for various neuropsychiatric presentations. Cureus. 2018, 10:e2304. 10.7759/cureus.2304

9. Moskowitz MA, Winickoff RN, Heinz ER: Familial calcification of the basal ganglions: a metabolic and genetic study. N Engl J Med. 1971, 285:72-77. 10.1056/NEJM197107082850202

10. Manyam BV: What is and what is not Fahr's Disease. Parkinsonism Relat Disord. 2005, 11:73-80. 


\section{Cureus}

10.1016/j.parkreldis.2004.12.001

11. Geschwind DH, Loginov M, Stern JM: Identification of a locus on chromosome 14q for idiopathic basal ganglia calcification (Fahr disease). Am J Hum Genet. 1999, 65:764 -72. 10.1086/302558

12. Yamada N, Hayashi T: Asymptomatic familial basal ganglia calcification with autosomal dominant inheritance: a family report (Article in Japanese). No To Hattatsu. 2000, 32:515 -19.

13. Dai X, Gao Y, Xu Z, et al.: Identification of a novel genetic locus on chromosome 8p21.1-q11.23 for idiopathic basal ganglia calcification. Am J Med Genet B Neuropsychiatr Genet. 2010, 153B:1305-10. 10.1002/ajmg.b.31102

14. da Silva RJ, Pereira IC, Oliveira JR: Analysis of gene expression pattern and neuroanatomical correlates for SLC20A2 (PiT-2) shows a molecular network with potential impact in idiopathic basal ganglia calcification ("Fahr's disease"). J Mol Neurosci. 2013, 50:280-83. 10.1007/s12031-013-0001-0

15. Avrahami E, Cohn DF, Feibel M, Tadmor R: MRI demonstration and CT correlation of the brain in patients with idiopathic intracerebral calcification. J Neurol. 1994, 241:381-84. 10.1007/BF02033355

16. Lauterbach EC, Cummings JL, Duffy J, et al.: Neuropsychiatric correlates and treatment of lenticulostriatal diseases: a review of the literature and overview of research opportunities in Huntington's, Wilson's, and Fahr's diseases. A report of the ANPA Committee on Research. American Neuropsychiatric Association. J Neuropsychiatry Clin Neurosci. 1998, 10:249-66. 10.1176/jnp.10.3.249

17. Ramos EM, Oliveira J, Sobrido MJ, Coppola G: Primary familial brain calcification. GeneReviews ${ }^{\circledR}$ (Internet). Adam MP, Ardinger HH, Pagon RA (ed): University of Washington, Seattle; 2004. NBK1421.

18. el Maghraoui A, Birouk N, Zaim A, Slassi I, Yahyaoui M, Chkili T: Fahr syndrome and dysparathyroidism. 3 cases (Article in French). Presse Med. 1995, 24:1301-304. 